Check for updates

Cite this: RSC Adv., 2019, 9, 36884

\title{
An enzyme-free FRET nanoprobe for ultrasensitive ketamine detection based on ATP-fueled target recycling $\dagger$
}

\author{
Hong Chen, \$Y Yun Zou, \$ Xue Jiang, Fangqi Cao and Wenbin Liu (DD* \\ Ketamine is a commonly abused drug due to its stimulant, dissociative and hallucinogenic effects. An \\ overdose of ketamine has been found to cause a variety of side effects. Therefore, the identification and \\ quantification of ketamine are of significant importance for clinical purposes and drug seizing. However, \\ conventional methods for ketamine detection possess some disadvantages such as sophisticated \\ procedures, expensive instruments and low sensitivity. Herein, we develop a novel fluorescent \\ nanoprobe for ultrasensitive ketamine detection with signal amplification based on Adenosine \\ Triphosphate (ATP)-fueled target recycling and FRET (fluorescence resonance energy transfer) occurring \\ between the FAM (Fluorescein, tagged with Y-shape DNA) and AuNPs. Based on the combination of \\ FRET and signals circle amplification, the gold nanospheres functionalized with Y-motif DNA (Y@AuNPs) \\ nanoprobe was utilized for effective ketamine detection with the limit of detection (LOD) down to 3 pg \\ $\mathrm{mL}^{-1}$, which was lower than previously reported. Furthermore, the high sensitivity of Y@AuNPs facilitated \\ quantitative analysis in biological media and practical samples.
}

Received 7th August 2019

DOI: $10.1039 / \mathrm{c} 9 \mathrm{ra} 06139 \mathrm{~h}$

rsc.li/rsc-advances
(ELISA $)^{17,18}$ have been proposed for the determination of ketamine. Although most of these methods possess some advantages in practical application, they require sophisticated procedures and expensive instruments. Recently, a novel chip paper based electrochemical sensor was designed for the detection of ketamine. ${ }^{\mathbf{1 9 , 2 0}}$ However, the limit of detection was not satisfactory for the demand of biosample analysis. ${ }^{21-23}$

As a low-cost and accurate analytical technique, fluorescence detection based on fluorescence resonance energy transfer (FRET) ${ }^{24-26}$ is promising for biosensor analysis. In addition, it can facilitate the enhancements of signals, which contributes to higher sensitivity. However, seldom work engineering FRET and enzyme-free amplification ${ }^{27-29}$ is designed and employed for ketamine detection.

Herein, we developed a novel fluorescent nanoprobe with signal amplification for ketamine detection. The stimuliresponsive Y-shaped DNA termed as Y-motif $^{30}$ was first designed for amplifying the signal, in which ATP was utilized as endogenous fuel for signal amplification through strand displacement (Scheme 1). Then, the FAM (Fluorescein, $\mathrm{C}_{20} \mathrm{H}_{12} \mathrm{O}_{5}$ )-tagged Y-motif was immobilized onto the surface of the synthesized gold nanospheres (AuNPs) by Au-S to construct the Y@AuNPs nanoprobes. Meanwhile the fluorescence resonance energy transfer (FRET) occurred from the excited FAM to AuNPs, which resulted in the fluorescence quenching of FAM. With the addition of ketamine and duplex strands-DNA (dsDNA), Ya dissociated from Y-motif to hybridize with SSDNA, and the aptamer of ketamine (K-Apt) released from dsDNA to combine with ketamine, resulting that the 
fluorescence of FAM recovered. Then, in the presence of sufficient ATP, Ya changed from chain-based structure to harpinbased structure owing to the interaction between the tail of Ya and ATP. At this time, after the combination of FRET and signals circle amplification, the Y@AuNPs nanoprobe was utilized for effective ketamine detection with the limit of detection (LOD) down to $3 \mathrm{pg} \mathrm{mL}^{-1}$, which was lower than previously reported. Furthermore, the high sensitivity of Y@AuNPs facilitated the quantitative analysis in the biological medium and practical samples.

\section{Experimental}

\section{Apparatus}

UV-Vis absorption spectra were recorded on a UV spectrophotometer (Cary 60, Agilent). Fluorescence spectrum was recorded on a fluorescence spectrophotometer (F-7000, Hitachi). Morphology of AuNPs was characterized using a high-resolution transmission electron microscope (HRTEM) (JEM-2100 Hitachi, Japan).

\section{Chemicals and materials}

Ketamine, methadone, cocaine and methamphetamine were obtained from Shanghai Research Institute of Criminal Science and Technology. Other chemicals used in this study, namely, ascorbic acid (Merck), bovine serum albumin (BSA) (SigmaAldrich), and sodium hydroxide ( $\mathrm{NaOH})$ (Merck) trisodium citrate and phosphate-buffered saline (PBS) (Sigma-Aldrich, Israel), chloroauric acid $\left(\mathrm{HAuCl}_{4} \cdot 4 \mathrm{H}_{2} \mathrm{O}\right)$ were provided by Shanghai Chemical Reagent Company (Shanghai, China). Human blood serums ( $\geq 99 \%$ ) were purchased from Solarbio Science \& Technology Co., Ltd. (Beijing, China). All of DNA were synthesized by Sangon Biotech Co. Ltd. (Shanghai, China) with standard desalting and used without further purification. Tris-

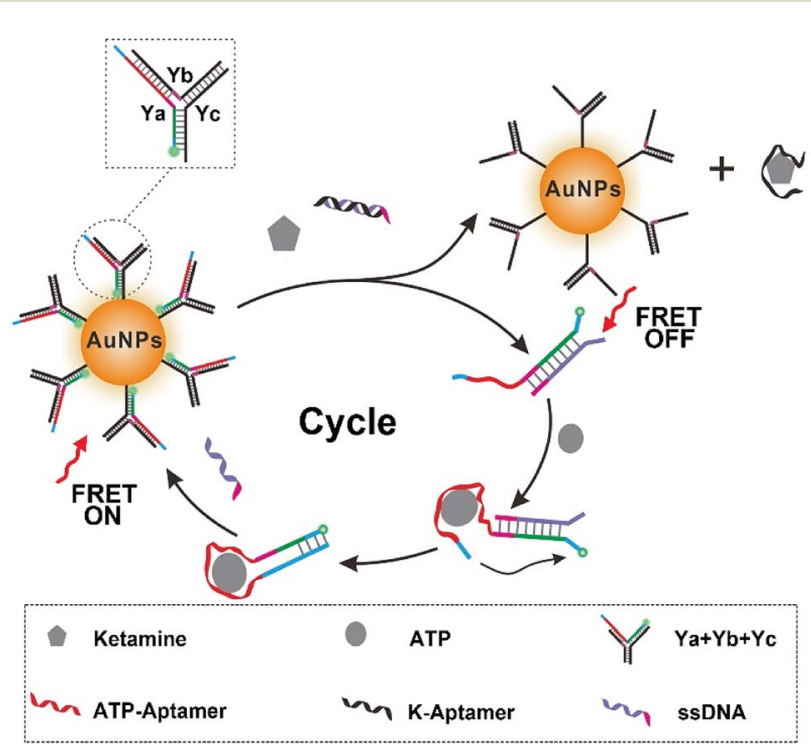

Scheme 1 Scheme illustration of fluorescence detection mechanism and signal cycle amplification process.
$\mathrm{HCl}(20 \mathrm{mM}, \mathrm{pH}=7.6)$ containing $146.0 \mathrm{mM} \mathrm{NaCl}, 5.0 \mathrm{mM} \mathrm{KCl}$, $5.0 \mathrm{mM} \mathrm{MgCl} 2$ was used in the DNA hybridization. The ultrapure water with a resistivity of $18.2 \mathrm{M} \Omega \mathrm{cm}^{-1}$ used in this work was prepared using a Milli-Q system (Hitachi, Japan). All the oligonucleotide sequences were listed in Table S1 of the ESI. $\dagger$ The aptamer of ketamine (K-Apt, ESI, Table S1 $\dagger$ ) was selected in our previous work using FluMag-SELEX and it could bind ketamine with high and specific abilities. ${ }^{31}$

\section{Preparation of $13 \mathrm{~nm}$ gold nanospheres (AuNPs)}

We used citrate stabilized gold nanoparticle synthesis method. Specifically speaking: $7 \mathrm{~mL}$ of $1 \%$ trisodium citrate $\left(\mathrm{C}_{6} \mathrm{H}_{7} \mathrm{Na}_{3}-\right.$ $\mathrm{O}_{8}$, M.W. 276.08) was added into a boiling solution of $\mathrm{HAuCl}_{4}$ $(200 \mathrm{~mL}, 0.01 \%)$ under stirring. When the color of solution changes from light yellow to deep red, stop heating and continue stirring for 20 minutes. The size of AuNPs was verified by UV-Vis spectrum and TEM imaging. The synthesis AuNPs were stored at $4{ }^{\circ} \mathrm{C}$ for further use.

\section{Preparation of Y-motif modified AuNPs}

In order to build ketamine drived signal cycle amplification system, the prepared $13 \mathrm{~nm}$ AuNPs were firstly functionalized with Y-motif. Typically, stoichiometric amounts of strands Ya, $\mathrm{Yb}$, and Yc were mixed in Tris- $\mathrm{HCl}$ buffer $(20 \mathrm{mM}, \mathrm{pH}=7.6)$; the mixture was incubated at $95{ }^{\circ} \mathrm{C}$ for $5 \mathrm{~min}$, and then sequentially cooled down to $65{ }^{\circ} \mathrm{C}, 60{ }^{\circ} \mathrm{C}, 55^{\circ} \mathrm{C}, 50{ }^{\circ} \mathrm{C}$, and $45^{\circ} \mathrm{C}$ (each step for $5 \mathrm{~min}$ ), $10 \mu \mathrm{L}$ of the mixture (Y-motif) were added into $100 \mu \mathrm{L}$ of $10 \mathrm{nM}$ AuNPs. Thereafter, 12.2 $\mu \mathrm{L}$ of citrate-HCl $(20 \mathrm{mM}, \mathrm{pH}=3)$ buffer was rapidly added into the mixture. After incubation for $30 \mathrm{~min}$, the solution was centrifuged (10 $000 \mathrm{rpm}, 15 \mathrm{~min}$ ) for three times to remove the unmodified Y-motif; the precipitate was washed for three times with Tris-

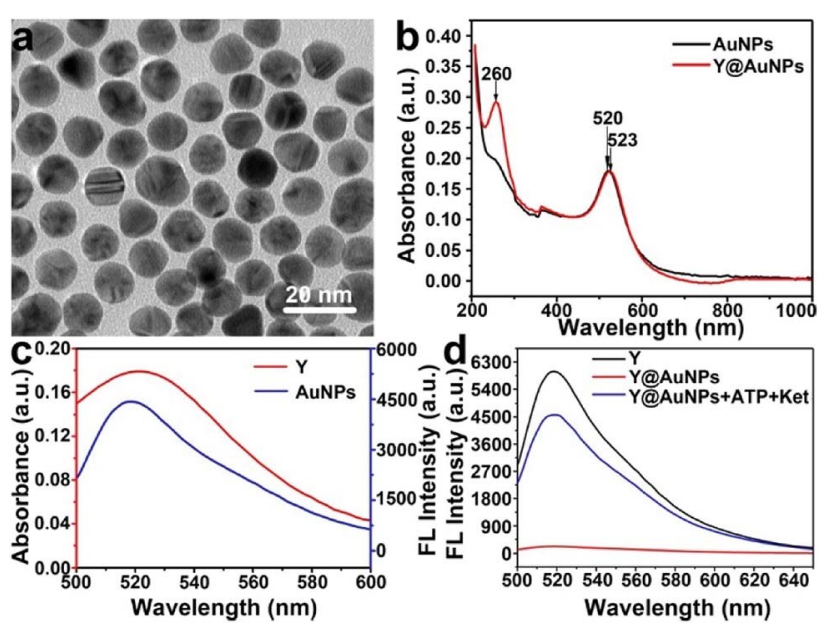

Fig. 1 (a) Transmission electron microscopy (TEM) image. (b) Ultraviolet-Vis (UV-Vis) absorption spectra of AuNPs and Y-motif immobilized AuNPs (Y@AuNPs). (c) Principle of fluorescence resonance energy transfer (FRET). The red and blue lines are attributed to UV-Vis absorption spectra of AuNPs and fluorescence emission spectra of $Y$ motif. (d) Feasibility of fluorescence detection with YaAuNPs probe. Fluorescence spectra of Y-motif (black line), Y@AuNPs (red line) and YaAuNPs with the addition of ATP and ketamine (blue line). 

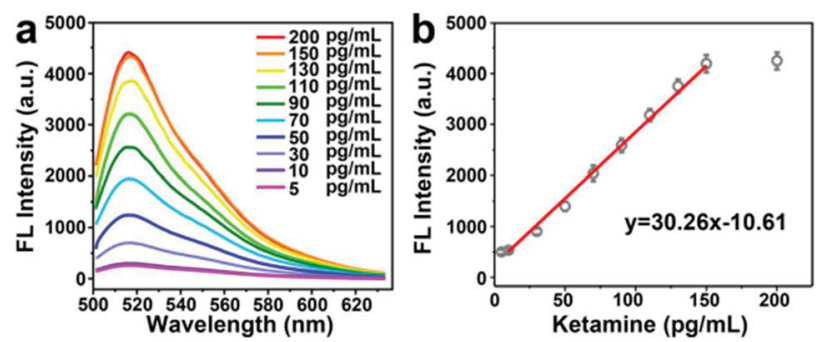

Fig. 2 (a) The fluorescence spectra of different concentrations of ketamine with Y@AuNPs in the presence of $10 \mathrm{mM}$ ATP. (b) The calibration curve corresponding to (a), in which the linear equation was $y$ $=30.26 x-10.61$.

$\mathrm{HCl}(20 \mathrm{mM}, \mathrm{pH}=7.6)$ and finally dispersed in $200 \mu \mathrm{L}$ Tris- $\mathrm{HCl}$ (20 mM, pH = 7.6). The concentration of the AuNPs was determined by measuring their absorbance at $520 \mathrm{~nm}$.

\section{Quantitative analysis of ketamine}

In order to test the sensitivity of our method, $3 \mu \mathrm{L}$ of $100 \mu \mathrm{M}$ ssDNA was firstly mixed with $3 \mu \mathrm{L}$ of $100 \mu \mathrm{M}$ ketamine aptamer and added $24 \mu \mathrm{L}$ Tris- $\mathrm{HCl}(20 \mathrm{nM}, \mathrm{pH}=7.6)$. The mixed solution was incubated at $95{ }^{\circ} \mathrm{C}$ for $10 \mathrm{~min}$ and then cooled to room temperature. The above mixture was added into $100 \mu \mathrm{L}$ of $30 \mathrm{nM}$ Y@AuNPs, followed by adding $50 \mu \mathrm{L}$ of ketamine at different concentrations $\left(200,150,130,110,90,70,50,30,10,5 \mathrm{pg} \mathrm{mL}^{-1}\right)$. To achieve the signal amplification, ATP $(10 \mathrm{mM})$ was added and incubated at $37^{\circ} \mathrm{C}$ for $1.5 \mathrm{~h}$ in Tris- $\mathrm{HCl}(20 \mathrm{mM}, \mathrm{pH}=7.6)$. Finally, the mixture was measured under fluorescence spectrophotometer at $\lambda_{\text {ex }} / \lambda_{\text {em }}=492 / 520 \mathrm{~nm}$.

\section{Selectivity of the proposed probe for ketamine detection}

To investigate the selectivity of the proposed nanoprobe for ketamine detection, the effect of a variety of non-specificity

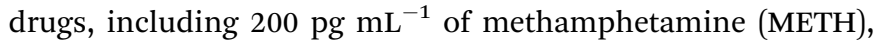
cocaine and methadone were checked under the optimum conditions. The ketamine with the concentration of $100 \mathrm{pg}$ $\mathrm{mL}^{-1}$ was selected as the control group. The changes of relative fluorescence intensities of reaction solution were detected by fluorescence spectroscopy.

\section{Analysis of ketamine in blood samples}

In order to investigate the possibility of the newly proposed nanoprobe to be applied for practical samples analysis, blood serum was taken as an example in this work. First of all, $2.0 \mathrm{~mL}$ of methanol was added to $2.0 \mathrm{~mL}$ of blood sample to separate the proteins. After shaking, the mixture was centrifuged for $10 \mathrm{~min}$ at $3500 \mathrm{rpm}$, and then the supernatant was diluted with $2.0 \mathrm{~mL}$ of PBS $(10 \mathrm{mM}, \mathrm{pH}=7.4)$ and spiked with standard ketamine solution.

\section{Results and discussion}

\section{Preparation and characteristics of Y@AuNPs nanoprobe}

As a starting point of this work, AuNP were prepared by a hydrothermal procedure. As shown in Fig. 1a and S1 in the ESI, $\dagger$ the transmission electron microscopic (TEM) image shows that AuNPs are highly uniform and the average particle size is estimated to be $13 \pm 2 \mathrm{~nm}$ based on the statistics of 100 nanoparticles. The ultraviolet-Vis (UV-Vis) absorption spectrum (black line) in Fig. 1b illustrates that AuNPs display intense absorption with a peak centered at $520 \mathrm{~nm}$. The UV-Vis absorption band of $520 \mathrm{~nm}$ of AuNPs red-shifted to $523 \mathrm{~nm}$, together with a new band at $260 \mathrm{~nm}$ generated, indicating the Ymotif is successfully immobilized onto the surface of AuNPs to form Y@AuNPs nanoprobe.

\section{Principle of FRET detection for ketamine}

Furthermore, the principle of FRET detection for ketamine was investigated. As shown in Fig. 1c, due to small distance between signal molecule (FAM) and AuNP and a spectral overlap between the emission spectrum of FAM centered at $520 \mathrm{~nm}$ and absorption spectrum of AuNP, the FRET occurred from FAM to AuNP (Fig. S2 $\dagger$ ). As shown in Fig. 1d, peaks around $525 \mathrm{~nm}$ were attributed to FAM. Fluorescence spectra shown in black and red lines illustrated that the fluorescence of Y-motif was quenched after the addition of AuNPs. However, in the simultaneous presence of ketamine and ATP, Ya dissociated from Y-motif to hybridize with ssDNA, and the aptamer of ketamine (K-Apt) released from dsDNA to combine with ketamine, resulting that the fluorescence of FAM recovered (blue line). Then, ATP as endogenous fuel triggered the next round. In this manner, the signal can be amplified, which was beneficial for detecting trace ketamine. These results indicated the feasibility of Y@AuNPs nanoprobe for fluorescence detection of ketamine.

\section{Optimization of detection conditions}

To evaluate the detection ability of Y@AuNPs nanoprobe for ketamine, the concentration of ATP was first studied. Fig. S3†

Table 1 Comparison of performance of different methods for detection of ketamine

\begin{tabular}{llll}
\hline Detection methods & Sample & Detection limit & Reference \\
\hline Elector-microchip & Urine-plasma & $50 \mathrm{ng} \mathrm{mL}^{-1}$ & 25 \\
LC/MS/MS & Hair & $20 \mathrm{ng} \mathrm{g}^{-1}$ & 26 \\
UPLC & Urine & $0.1 \mathrm{ng} \mathrm{mL}^{-1}$ & 18 \\
GC-MS & Urine & $0.5-1.0 \mathrm{ng} \mathrm{mL}^{-1}$ & $90 \mathrm{pg} \mathrm{mL}^{-1}$ \\
Fluorescence & Blood & $3 \mathrm{pg} \mathrm{mL}^{-1}$ & 32
\end{tabular}


revealed that the strand displacement kinetics was finely controlled by varying the concentrations of ATP. The signals were efficiently enhanced with the fueling ATP in the range from $1 \mathrm{mM}$ to $10 \mathrm{mM}$. In addition, upon the addition of ketamine $\left(200 \mathrm{pg} \mathrm{mL}^{-1}\right)$ and excess ATP, fluorescence intensity of FAM gradually increased with the prolong time, and remained unchanged until $1.5 \mathrm{~h}$ (Fig. S4 $\dagger$ ). Thus, the reaction time was optimized to be $1.5 \mathrm{~h}$. Then, the stability of Y@AuNPs under various $\mathrm{pH}$ was demonstrated in Fig. S5. $\dagger$ The fluorescence intensity of FAM was observed to retain stable in the $\mathrm{pH}$ range of 3.0-11.0 in the presence of $120 \mathrm{pg} \mathrm{mL}^{-1}$ ketamine. In consideration of human physiological environment, $\mathrm{pH} 7.6$ was chosen as the optimal one in the following experimental procedures.

\section{Quantitative measurement of ketamine}

Based on the above optimized conditions, the detection ability of Y@AuNPs for ketamine was further investigated. As shown in Fig. 2a, in the presence of $10 \mathrm{mM}$ ATP, the fluorescence intensity of FAM increased gradually with the increasing concentration of ketamine. Meanwhile, the fluorescence intensity exhibited good linearity with the concentration of ketamine in the range from $10 \mathrm{pg} \mathrm{mL}{ }^{-1}$ to $150 \mathrm{pg} \mathrm{mL}^{-1}$ with the limit of detection (LOD) of $3 \mathrm{pg} \mathrm{mL} \mathrm{m}^{-1}$ at $3 \sigma$. The LOD of the developed Y@AuNPs for ketamine was compared with those of other works reported previously, with the comparison results shown in Table 1. In previous studies, the estimated detection limit of ketamine in blood using novel fluorescence genosensor is 0.06 $\mathrm{ng} \mathrm{mL}^{-1}$. Accordingly, the developed fluorescent nanoprobe can display better detection ability.

\section{Selectivity analysis of Y@AuNPs for ketamine detection}

Then, the specificity of this Y@AuNPs nanoprobe was further evaluated by comparing the fluorescence signal response measured for these four kinds of drugs, including target ketamine (100 pg $\left.\mathrm{mL}^{-1}\right)$, methadone, cocaine and methylamphetamine (METH) at the same concentration of $200 \mathrm{pg}$ $\mathrm{mL}^{-1}$. As shown in Fig. $3 \mathrm{a}$ and $\mathrm{b}$, the relative fluorescence intensities change of Y@AuNPs for the interfering substances (methadone, cocaine and METH) were very small, while ketamine showed significant increase of fluorescence. These

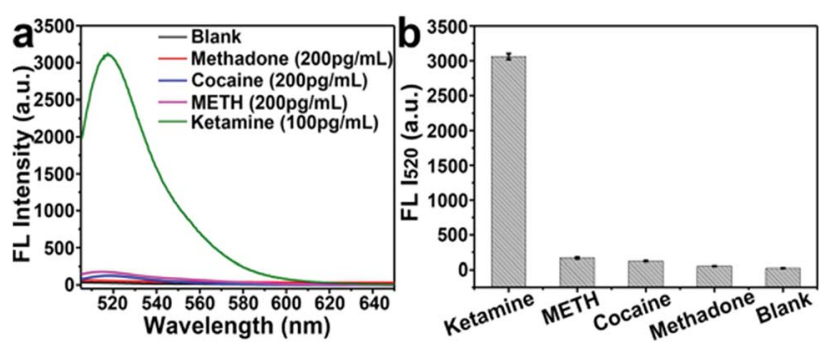

Fig. 3 (a) Evolution of the selectivity. The fluorescence spectra of the ketamine detection system toward the four various drugs including ketamine $\left(100 \mathrm{pg} \mathrm{mL}^{-1}\right)$, methadone, cocaine and methamphetamine (METH) with the concentration of $200 \mathrm{pg} \mathrm{mL}^{-1}$. (b) The corresponding fluorescence bars chart for specificity detection.
Table 2 Determination of ketamine in human blood samples $(n=5)$

\begin{tabular}{lllll}
\hline Sample & $\begin{array}{l}\text { Detected } \\
\left(\mathrm{pg} \mathrm{mL} \mathrm{mL}^{-1}\right)\end{array}$ & $\begin{array}{l}\text { Added } \\
\left(\mathrm{pg} \mathrm{mL} \mathrm{mL}^{-1}\right)\end{array}$ & $\begin{array}{l}\text { Recovery } \\
(\%)\end{array}$ & RSD (\%) \\
\hline Blood & - & Blank & - & - \\
& 11.8 & 10 & 118 & 4.5 \\
& 31.8 & 30 & 106 & 3.7 \\
& 48.5 & 50 & 97 & 4.8 \\
& 135 & 100 & 93 & 3.3 \\
& 130 & 90 & 2.6
\end{tabular}

results indicated that our designed probe exhibited a good selectivity to discriminate ketamine and the other drugs.

\section{Quantitative analysis of ketamine in simulated blood samples}

The excellent detection ability of Y@AuNPs enabled it to be a reliable approach for quantitative analysis in biological medium. For practical application, the fluorescence sensor for ketamine detection in blood samples was performed using the standard addition method. The certain amounts of ketamine were added to the prepared samples and the ketamine concentration was measured by the proposed sensor. Five measurements were performed at each concentration. The experimental results were summarized in Table 2. As depicted, the obtained recoveries were in the range of 95-110\% with RSDs less than $4.2 \%$, which demonstrated the capability of the proposed Y@AuNPs for determination of ketamine in biological samples.

\section{Conclusions}

In summary, we have successfully developed a novel Y@AuNPs fluorescent nanoprobe composed of AuNP and Y-motif DNA structure for ketamine detection by FRET effect. The sufficient ATP in biological medium was termed as fuel, which can realize the signal amplification for improving the sensitivity for ketamine detection in coordination with Y-motif. The LOD was down to $3 \mathrm{pg} \mathrm{mL} \mathrm{m}^{-1}$, which was lower than previously reported. In addition, the nanoprobe showed good selectivity towards ketamine. Furthermore, the acceptable recoveries which obtained from the practical sample analysis, revealed that the performance of the developed nanoprobe was not affected significantly by the matrix of the practical samples and the proposed Y@AuNPs can be used for determination of ketamine in blood samples.

\section{Conflicts of interest}

There are no conflicts to declare.

\section{Acknowledgements}

This work was sponsored by Shanghai Scientific and Technological Innovation Project (16dz1205600, 17DZ1205400 and 19dz1200400), Program of Shanghai Academic/Technology 
Research Leader (19XD1432700), Shanghai Rising-Star Program (18QB1403400 and 19QB1405200), National Natural Science Foundation of China (21704110), Natural Science Foundation of Shanghai (19ZR1449500 and 19ZR1449400), Science and Technology Development Fund of Shanghai Municipal Public Security Bureau (2018002 and 2018003), which we gratefully acknowledged.

\section{References}

1 P. S. K. Chu, W. K. Ma, S. C. W. Wong, R. W. H. Chu, C. H. Cheng, S. Wong, J. M. I. Tse, F. L. Lau, M. K. Yiu and C. W. Man, The destruction of the lower urinary tract by ketamine abuse: A new syndrome, BJU Int., 2010, 102, 1616-1622.

2 J. M. Felser and D. J. Orban, Dystonic reaction after ketamine abuse, Ann. Emerg. Med., 1982, 11, 673-675.

3 A. C. Lahti, M. A. Weiler, B. T. Michaelidis, A. Parwani and C. A. Tamminga, Effects of ketamine in normal and schizophrenic volunteers, Neuropsychopharmacology, 2001, 25, 455-467.

4 R. M. Berman, A. Cappiello, A. Anand, D. A. Oren, G. R. Heninger, D. S. Charney and J. H. Krystal, Antidepressant effects of ketamine in depressed patients, Biol. Psychiatry, 2000, 47, 351-354.

5 J. H. Krystal, L. P. Karper, J. P. Seibyl, G. K. Freeman, R. Delaney, J. D. Bremner, G. R. Heninger, M. B. Bowers and D. S. Charney, Subanesthetic effects of the noncompetitive NMDA antagonist, ketamine, in humans. Psychotomimetic, perceptual, cognitive, and neuroendocrine responses, Arch. Gen. Psychiatry, 1994, 51, 199-214.

6 Q. Deng, Q. Tang, R. S. Schottenfeld, W. Hao and M. C. Chawarski, Drug use in rural China: a preliminary investigation in Hunan Province, Addiction, 2012, 107, 610613.

7 K. Xu and R. H. Lipsky, Repeated ketamine administration alters N-methyl-D-aspartic acid receptor subunit gene expression: implication of genetic vulnerability for ketamine abuse and ketamine psychosis in humans, Exp. Biol. Med., 2015, 240, 145-155.

$8 \mathrm{H}$. V. Curran and L. Monaghan, In and out of the K-hole: a comparison of the acute and residual effects of ketamine in frequent and infrequent ketamine users, Addiction, 2001, 96, 749-760.

9 J. M. White and C. F. Ryan, Pharmacological properties of ketamine, Drug Alcohol Rev., 1996, 15, 145-155.

10 Y. Fan, Y. Q. Feng, S. L. Da and X. P. Gao, In-tube solid-phase microextraction with poly(methacrylic acid-ethylene glycol dimethacrylate) monolithic capillary for direct highperformance liquid chromatographic determination of ketamine in urine samples, Analyst, 2004, 129, 1065-1069.

11 P. Li, H. Han, X. Zhai, W. He, L. Sun and J. Hou, Simultaneous HPLC-UV determination of ketamine, xylazine, and midazolam in canine plasma, J. Chromatogr. Sci., 2012, 50, 108-113.
12 M. K. Huang, C. Liu, J. H. Li and S. D. Huang, Quantitative detection of ketamine, norketamine, and dehydronorketamine in urine using chemical derivatization followed by gas chromatography-mass spectrometry, J. Chromatogr. B: Anal. Technol. Biomed. Life Sci., 2005, 820, 165-173.

13 H. R. Lin and A. C. Lua, A fast GC-MS screening procedure for ketamine and Its metabolites in urine samples, J. Food Drug Anal., 2005, 13, 107-111.

14 L. G. Apollonio, D. J. Pianca, I. R. Whittall, W. A. Maher and J. M. Kyd, A demonstration of the use of ultra-performance liquid chromatography-mass spectrometry [UPLC/MS] in the determination of amphetamine-type substances and ketamine for forensic and toxicological analysis, $J$. Chromatogr. B: Anal. Technol. Biomed. Life Sci., 2006, 836, 111-115.

15 J. Y. Cheng and V. K. Mok, Rapid determination of ketamine in urine by liquid chromatography-tandem mass spectrometry for a high throughput laboratory, Forensic Sci. Int., 2004, 142, 9-15.

16 I. R. Miksa, M. R. Cummings and R. H. Poppenga, Determination of acepromazine, ketamine, medetomidine, and xylazine in serum: multi-residue screening by liquid chromatography-mass spectrometry, J. Anal. Toxicol., 2005, 29, 544-551.

17 P. S. Cheng, C. Y. Fu, C. H. Lee, C. Liu and C. S. Chien, GCMS quantification of ketamine, norketamine, and dehydronorketamine in urine specimens and comparative study using ELISA as the preliminary test methodology, $J$. Chromatogr. B: Anal. Technol. Biomed. Life Sci., 2007, 852, 443-449.

$18 \mathrm{~J}$. H. Watterson and T. C. J. VandenBoer, Effects of tissue type and the dose-death interval on the detection of acute ketamine exposure in bone and marrow with solid-phase extraction and ELISA with liquid chromatography-tandem mass spectrometry confirmation, J. Anal. Toxicol., 2008, 32, 63-638.

19 V. B. C. Lee, N. F. Mohd-Naim, E. Tamiya and M. U. Ahmed, Trends in paper-based electrochemical biosensors: from design to application, Anal. Sci., 2018, 34, 7-18.

20 J. Narang, N. Malhotra, C. Singhal, A. Mathur, D. Chakraborty, A. Anil, A. Ingle and C. S. Pundir, Point of care with micro fluidic paper based device integrated with nano zeolite-graphene oxide nanoflakes for electrochemical sensing of ketamine, Biosens. Bioelectron., 2017, 88, 249-257.

21 T. Kawasaki, M. Ogata, C. Kawasaki, J. I. Ogata, Y. Inoue and A. Shigematsu, Ketamine suppresses proinflammatory cytokine production in human whole blood in vitro, Anesth. Analg., 1999, 89, 665.

22 A. C. Lahti, H. H. Holcomb, D. R. Medoff and C. A. Tamminga, Ketamine activates psychosis and alters limbic blood flow in schizophrenia, NeuroReport, 1995, 6, 869-872.

23 K. A. Moore, J. Sklerov, B. Levine and A. J. Jacobs, Urine concentrations of ketamine and norketamine following illegal consumption, J. Anal. Toxicol., 2001, 25, 583-588. 
24 R. Heim and R. Y. Tsien, Engineering green fluorescent protein for improved brightness, longer wavelengths and fluorescence resonance energy transfer, Curr. Biol., 1996, 6, 178-182.

25 X. L. Zhang, Y. Xiao and X. H. Qian, A Ratiometric Fluorescent Probe Based on FRET for Imaging $\mathrm{Hg}^{2+}$ Ions in Living Cells, Angew. Chem., Int. Ed., 2008, 47, 8025-8029.

26 H. Tian, L. Ip, H. Luo, D. Chang and K. Luo, A high throughput drug screen based on fluorescence resonance energy transfer (FRET) for anticancer activity of compounds from herbal medicine, Br. J. Pharmacol., 2007, 150, 321-334.

27 L. Li, J. Feng, H. Liu, Q. Li, L. Tong and B. Tang, Two-color imaging of microRNA with enzyme-free signal amplification via hybridization chain reactions in living cells, Chem. Sci., 2015, 7, 1940-1945.

28 L. Yang, C. Liu, W. Ren and Z. Li, Graphene surfaceanchored fluorescence sensor for sensitive detection of microRNA coupled with enzyme-free signal amplification of hybridization chain reaction, ACS Appl. Mater. Interfaces, 2012, 4, 6450-6453.

29 A. X. Zheng, J. Li, J. R. Wang, X. R. Song, G. N. Chen and H. H. Yang, Enzyme-free signal amplification in the DNAzyme sensor via target-catalyzed hairpin assembly, Chem. Commun., 2012, 48, 3112-3114.

30 P. Zhang, C. Wang, J. Zhao, A. Xiao, Q. Shen, L. Li, J. Li, J. Zhang, Q. Min and J. Chen, Near infrared-guided smart nanocarriers for microRNA-controlled release of doxorubicin/siRNA with intracellular ATP as fuel, ACS Nano, 2016, 10, 3637-3647.

31 M. Sun, F. Cao, X. Hu, Y. Zhang, X. Lu and L. Zeng, DNA Aptamer Selection in vitro for Determining Ketamine by FluMag-SELEX, J. Forensic Med., 2014, 30, 346-349.

32 Y. Ding, X. Li, Y. Guo, J. Yan, J. Ling, W. Li and L. Zha, Rapid and sensitive detection of ketamine in blood using novel fluorescence genosensor, Anal. Bioanal. Chem., 2017, 409, 7027-7034. 